of fatty acids of unusual and characteristic composition may be present. The proportion of the 'essential' cis, cis linoleic acid in the animal fats is low. Striking differences occur in glyceride composition, and lard may be regarded as the fat which differs most considerably from the vegetable type, with beef tallow or human depot fat being somewhat more random in composition. In the non-fatty components of the two groups the most significant differences arise in the sterols and vitamins. Cholesterol is the main sterol present in animal fats, whereas it is almost entirely absent in the vegetable group. Moreover, vitamin $\mathrm{E}$ is characteristic of vegetable fats and is almost entirely absent in the animal group.

These differences in composition indicate a profound difference in the in vivo synthesis of fats in the animal and vegetable species.

\title{
REFERENCES
}

Cousins, E. R., Guice, W. A. \& Feuge, R. O. (1959). 7. Amer. Oil Chem. Soc. 36, 24.

Devine, J. \& Williams, P. N. (editors) (1961). The Chemistry and Technology of Edible Oils and Fats. Unilever Conference. Oxford: Pergamon Press.

Hansen, R. P., Shorland, F. B. \& Cooke, N. J. (1957). Nature, Lond., 179, 98.

Hansen, R. P., Shorland, F. B. \& Cooke, N. J. (1959). Chem. E' Ind. p. I24.

Keppler, J. G. (1957). Rec. Trav. Chim. 76, 49.

MacGee, J., Mattson, F. H. \& Beck, L. W. (1958). In Essential Fatty Acids, p. 21. [H. M. Sinclair, editor.] London: Butterworths Scientific Publications.

Mattson, F. H. (1960). F. Nutr. 7r, 366.

Van Beers, G. J., Sparreboom, S. \& Keppler, J. G. (1958). In Essential Fatty Acids, p. I6. [H. M. Sinclair, editor.] London: Butterworths Scientific Publications.

\section{Animal and vegetable fats as human foods}

\section{By H. M. Sinclair, Magdalen College, Oxford}

A human food is what is ingested by man and provides one or more aliments and nutrients. A good food should not contain high concentrations of noxious substances such as carcinogens, toxins and antivitamins. The undesirability of such substances may be relative: the amounts of saturated fatty acids, cholesterol, hydroperoxides, and polymers or isomers of fatty acids may be significant in relation to the amounts of certain unsaturated fatty acids and of tocopherols. Neither processing nor additions (such as DDT) will be considered.

Fat is an obligatory dietary constituent for the supply of essential fatty acids and for no other known reason. It is a desirable dietary constituent for several reasons. First, it supplies to a person on an average mixed diet slightly less than 9 available $\mathrm{kcal} / \mathrm{g}$ whereas carbohydrate or protein supplies about $4 \mathrm{kcal}$. There are differences in animal and vegetable fats; the former supplied about $8.95 \mathrm{kcal}$ and the latter $8.35 \mathrm{kcal}$ in the diets studied by Atwater \& Bryant (1900); this was caused to a slight degree by differences in heat of combustion (animal fat, $9.40 \mathrm{kcal} / \mathrm{g}$; vegetable fat, 9.30 $\mathrm{kcal} / \mathrm{g}$ ) but to a greater extent by differences in losses in digestion (availability of animal fat, $95 \%$; of vegetable fat, $90 \%$ ). Secondly, fat is desirable for increasing the palatability of food and for decreasing hunger between meals, but there is no obvious 
difference between animal and vegetable fats in these respects. Thirdly, fats can be sources of the fat-soluble vitamins $\mathrm{A}, \mathrm{D}, \mathrm{E}$ and $\mathrm{K}$. The body, however, obtains much of its vitamin A from ingested carotenoids in green leafy vegetables. No vegetable fat contains vitamin A but $\beta$-carotene occurs occasionally in vegetable oils, red palm oil being an excellent source. Some animal fats, such as butter, contain both vitamin $A$ and $\beta$-carotene. Vitamins $D$ are found only rarely in animal fats and never in vegetable fats. The tocopherols are in general very much more plentiful in vegetable than in animal fats, and in the former there is in general a correlation between the iodine value and the tocopherol content. It is not always so: safflowerseed oil (iodine value, ${ }_{13} 3^{-}-150$; linoleic-acid content about $78 \%$ ) is a good drying oil because of its low tocopherol content, whereas maize (corn) oil (iodine value, Iro-I30; linoleic-acid content about $55 \%$ ) is relatively stable. Indeed, maize oil has not only a high content of tocopherols (about $0.1 \%$ ) but also a particularly good mixture $(89 \% \gamma$-tocopherol and most of the rest $\alpha$-tocopherol) since $\gamma$-tocopherol is the more powerful anti-oxidant and so protects maize oil when stored on the shelf or in the intestine but is not absorbed from the intestine, whereas $\alpha$-tocopherol is readily absorbed and so protects the linoleic acid from hydroperoxide formation within the body.

There are various minor points about dietary fats that have been studied largely upon lower animals and need not concern us. These include the sparing action on thiamine (Evans \& Lepkovsky, 1929), the sparing action on protein, and their ability to increase capacity for work, to increase length of survival during fasting, and to increase resistance to certain forms of stress.

\section{Some chemical characteristics of animal and vegetable fats}

The most prevalent fats in animals and plants are triglycerides. The longer and more saturated the fatty acids in these the higher is the melting point of the compound. In general the typical triglycerides remain liquid in the living organism, and therefore marine animals and Arctic plants have unusually high proportions of unsaturated fatty acids. Many unusual compounds are found in plants: the fat of laurel seeds contains about $30 \%$ of trilaurin; tung oil contains about $83 \%$ elaeostearic acid; coconut oil and palm-kernel oil contain $40-50 \%$ lauric and $15-20 \%$ myristic acids.

The commonest unsaturated fatty acid throughout nature is oleic acid, which the body can make from carbohydrate or from its usual saturated fatty acids, palmitic and stearic. Phospholipids--which occur for instance in cell membranes, the endoplasmic reticulum and mitochondrial membranes and cristae-characteristically contain large proportions of linoleic and arachidonic acids; saturated fatty acids when present are in the $\beta$-position with an unsaturated acid in the $\alpha$-position. Arachidonic acid is found only in animal tissues, never occurring in plants. Cardiolipin, a complex phosphatidic acid, normally has as its fatty acids a mixture of linoleic and oleic in the ratio of $5: \mathrm{I}$. The fatty acids of the sphingomyelins are mainly saturated, the most typical being lignoceric $\left(\mathrm{C}_{24}\right)$. 
Cholesterol is the characteristic sterol of animals but does not occur in plants, in which $\beta$-sitosterol is important in the higher ones and ergosterol in fungi; cholesterol is normally esterified mainly with linoleic acid and transported as such in $\alpha$-lipoproteins, but occurs free in cellular and mitochondrial membranes. Waxes, which are esters of fatty acids with higher aliphatic alcohols, occur in the cuticles of leaves and fruits, in the secretion of insects (e.g. bees-wax) and in the depot fats of certain aquatic animals such as whales. In others, such as sharks, the higher aliphatic alcohols may be linked as esters with an hydroxyl of glycerol giving chimyl, batyl and selachyl alcohols.

Because of their importance as foods, special mention must be made of the fats of ruminants (e.g. cows, sheep, deer). Except for them, almost all the unsaturated fatty acids in nature have the cis configuration although there are minor exceptions in plants (e.g. elaeostearic acid in tung oil). Further, almost all the natural polyenoic acids have the divinyl-methane grouping (elaeostearic acid being an obvious exception). The main fatty acid of pasture lipids is linolenic acid, but the body fats of pasture-fed ruminants contain little if any of it because during digestion in the rumen micro-organisms change it and other unsaturated fatty acids in a manner similar to the catalytic hydrogenation performed by the margarine manufacturer; saturated fatty acids such as stearic are found as well as trans isomers of unsaturated ones (Shorland, 1950). Hence the fat of cow's milk is in a sense a processed fat-it has been formed by a process of hydrogenation and isomerization carried out by micro-organisms in the rumen of the cow. What little 'natural' linoleic acid escapes this processing is retained by the cow mainly for its essential bodily purposes; and the saturated fatty acids and trans isomers, which are useful mainly as a source of energy, are put into depot fat or milk. Therefore cow's milk contains very much less essential fatty acids than does human milk. The horse and ass do not have a ruminant

Table I. Fatty-acid contents of some animal and vegetable fats $(\%$, by weight) (mainly from Hilditch, 1956)

\begin{tabular}{|c|c|c|c|c|c|c|c|c|c|c|c|c|c|}
\hline \multirow[b]{2}{*}{$\begin{array}{l}\text { Acids } \\
\text { turated: }\end{array}$} & \multicolumn{7}{|c|}{ Depot fat } & \multirow[b]{2}{*}{$\begin{array}{c}\text { Maize } \\
\text { oil }\end{array}$} & \multirow[b]{2}{*}{$\begin{array}{l}\text { Olive } \\
\text { oil }\end{array}$} & \multicolumn{4}{|c|}{ Milk fat } \\
\hline & Cow 5 & Sheep & Horse & Man & Pig & $\begin{array}{l}\text { Chic- } \\
\text { ken }\end{array}$ & Whale & & & Cow & Horse & Man & Whale \\
\hline $\mathrm{C}_{14}$ and below & 3 & 3 & 5 & 6 & $\mathbf{I}$ & I & 9 & 0 & $\mathbf{r}$ & 25 & 22 & 15 & 8 \\
\hline Palmitic $\left(\mathrm{C}_{18}\right)$ & 29 & 25 & 26 & 25 & 30 & 25 & 15 & 13 & 10 & 25 & 16 & 23 & 17 \\
\hline Stearic $\left(\mathrm{C}_{18}\right)$ & $2 \mathrm{I}$ & 28 & 5 & 6 & I6 & 4 & 4 & 3 & I & 9 & 3 & 7 & 2 \\
\hline $\mathrm{C}_{20}$ and above & $\mathbf{I}$ & $\circ$ & Trace & $x$ & 0 & 0 & $\mathbf{I}$ & 0 & $\circ$ & $\mathbf{I}$ & 0 & $\mathbf{I}$ & 0 \\
\hline $\begin{array}{l}\text { Mono-unsaturated: } \\
\text { Palmitoleic }\left(\mathrm{C}_{16}\right) \\
\text { Oleic }\left(\mathrm{C}_{18}\right)\end{array}$ & $\begin{array}{c}3 \\
4 I^{*}\end{array}$ & $\begin{array}{c}\mathbf{I} \\
37^{*}\end{array}$ & $\begin{array}{r}7 \\
34\end{array}$ & $\begin{array}{r}7 \\
45\end{array}$ & $\begin{array}{r}3 \\
4 I\end{array}$ & $\begin{array}{r}7 \\
43\end{array}$ & $\begin{array}{l}r_{4} \\
33\end{array}$ & $\begin{array}{r}0 \\
31\end{array}$ & $\begin{array}{r}\circ \\
80\end{array}$ & $\begin{array}{c}4 \\
30^{*}\end{array}$ & $\begin{array}{r}7 \\
19\end{array}$ & $\begin{array}{r}5 \\
36\end{array}$ & $\begin{array}{c}6 \\
18(?)\end{array}$ \\
\hline $\begin{array}{l}\text { Polyunsaturated: } \\
\text { Linoleic }\left(\mathrm{C}_{18}: 2\right) \\
\text { Linolenic }\left(\mathrm{C}_{18}: 3\right) \\
\text { Arachidonic }\left(\mathrm{C}_{20}: 4\right) \\
\mathrm{C}_{22} \text { and higher }\end{array}$ & $\begin{array}{c}2^{*} \\
0 \\
\text { Trace }\end{array}$ & $\begin{array}{l}5^{*} \\
0 \\
1\end{array}$ & $\begin{array}{r}5 \\
16 \\
2\end{array}$ & $\begin{array}{l}8 \\
0 \\
2\end{array}$ & $\begin{array}{l}7 \\
0 \\
2\end{array}$ & $\begin{array}{r}18 \\
0 \\
1\end{array}$ & $\begin{array}{l}0 \\
4\end{array}$ & $\begin{array}{r}53 \\
0 \\
0\end{array}$ & $\begin{array}{l}7 \\
0 \\
0\end{array}$ & $\begin{array}{c}4^{*} \\
0 \\
\operatorname{tr}\end{array}$ & $\begin{array}{r}8 \\
16 \\
5\end{array}$ & $\begin{array}{l}8 \\
0 \\
3\end{array}$ & $\begin{array}{c}? \\
9(?) \\
26(?) \\
13\end{array}$ \\
\hline
\end{tabular}

* Mainly trans isomers in linoleic acid, and partly in oleic acid. 
digestion and so have much linolenic acid in their milks. Approximate compositions of some animal and vegetable fats are given in Table $\mathrm{I}$.

The plant synthesizes its fats, and these are therefore of fairly constant composition for a given plant in a given locality. The animal obtains its fats partly from those ingested and absorbed (e.g. the essential fatty acids) and partly from fatty acids made within the body. In general therefore the fats of a particular animal species are much more variable than those of a plant species. This variation is important to human nutrition in various ways, and I want to emphasize one: alterations in the feeding of animals for human food may make important alterations in the composition of the food. The pig affords a useful example. Until about the beginning of the Second World War it was customary to keep pigs free-ranging and give them relatively unsaturated fats that produced 'soft' fat on the pig (which means relatively unsaturated fat); at that time lard, which was rendered by and bought from the butcher, was an excellent source of essential fatty acids and indeed was often used in experimental animal diets for supplying them. At about the time of the Second World War the public was supposed to want 'hard' fat and therefore a change was made in the usual method of feeding pigs, highly unsaturated fats being drastically cut and carbohydrates being increased. Pig fat therefore became a poor source of essential fatty acids. Further, lard became a packaged food sold by a grocer; it therefore has to have a long shelf-life and is usually hydrogenated. This has been a general tendency in our foods - to eliminate essential fatty acids because their ease of oxidation with production of rancidity is a nuisance to the food manufacturer and seller. Consequent alterations in composition of foods have not been adequately considered by those (Hollingsworth, Vaughan \& Warnock, I957; McCann \& Trulson, 1957) who maintain that the dietary ratio of essential to non-essential fatty acids has not decreased in the last few decades.

\section{Polyunsaturated and essential fatty acids}

These terms are not synonymous. The work of Klenk, Thomasson and particularly Mead (see Mead (I960) for references) has shown that there are four main classes of straight-chain unsaturated fatty acids, distinguished by the position of the first double bond counting from the methyl end. These are the linolenic $(\triangle 3,4)$, linoleic $(\triangle 6,7)$, palmitoleic $(\triangle 7,8)$, and oleic $(\triangle 9,10)$ families. Mead in particular has shown very elegantly that the animal body can add two carbons to (for instance) linoleic acid to give $\gamma$-linolenic acid, then add two more carbons through acetylcoenzyme $A$, then insert another double bond (giving arachidonic acid). In general this process can be repeated until the double-bond system approaches to within three or four carbon atoms of the carboxyl end. Obviously the longest and most highly unsaturated acids from these families will arise from linolenic acid, which can give rise to a $\mathrm{C}_{22}$ acid with five double bonds, $\mathrm{CH}_{3} \cdot\left(\mathrm{CH}_{2} \mathrm{CH}=\mathrm{CH}\right)_{5} \cdot\left(\mathrm{CH}_{2}\right)_{5}$. $\mathrm{COOH}$, and possibly a $\mathrm{C}_{22}$ with six double bonds, $\mathrm{CH}_{3} \cdot\left(\mathrm{CH}_{2} \cdot \mathrm{CH}=\mathrm{CH}\right)_{6} \cdot\left(\mathrm{CH}_{2}\right)_{2}$. $\mathrm{COOH} ; \mathrm{C}_{22}$ acids with five and six double bonds do occur in ox liver and fish. Fish in particular have these linolenic-class highly unsaturated fatty acids. Theoretically, the longest and most unsaturated fatty acids should arise in the body from the 
twelve-carbon acid with one double bond in the $\mathrm{I}: 2$ position from the methyl end, $\mathrm{CH}_{2}=\mathrm{CH} .\left(\mathrm{CH}_{2}\right)_{9} . \mathrm{COOH}$, and this I hope to test; it might be the precursor of the most powerful cholesterol-lowering fatty acid.

Fatty acids of the linoleic and linolenic classes are essential fatty acids. The former (linoleic, $\gamma$-linolenic and arachidonic) have full activity for animals so far tested: for instance they permit growth on fat-deficient diets and prevent dermatitis produced by such diets. The linolenic-class acids do the former but not the latter. The oleic and palmitoleic classes can be made in the body from saturated fatty acids or carbohydrates and do neither; indeed, the two eicosatrienoic acids of these classes have been shown by Mead (1960) to accumulate in deficiency of essential fatty acids, which could be interpreted teleologically as an attempt by the body to make polyunsaturated fatty acids in the absence of those it needs.

It will be apparent that polyunsaturated and essential fatty acids are not synonymous. Does the difference matter?

\section{Influence of some fats on blood lipids}

Total fat in the diet. In various publications Keys maintained (e.g. Keys, 1953) that all fats were equal in raising serum cholesterol level and causing atherosclerosis. On the other hand, Kinsell (Kinsell, Partridge, Boling, Margen \& Michaels, 1952), Groen (Groen, Tjiong, Kamminga \& Willebrands, 1952) and Ahrens (Ahrens, Blankenhorn \& Tsaltas, 1954) showed that there was a tendency for animal fats to raise serum cholesterol level and for unprocessed vegetable fats to lower it. Some of the earlier work was briefly listed by Kinsell \& Sinclair (1957). No one would now maintain that total dietary fat is the important factor in this context. It is, however, important in ketosis.

Quality of fat in the diet. So far as the raising or lowering of serum cholesterol level is concerned, quality is important. But the contrast is not between animal and vegetable: some animal fats (e.g. butter) tend to raise it, others (e.g. fish oils) to lower it; some vegetable fats (e.g. coconut oil) raise it, others (e.g. maize oil) lower it. The question whether the raising or lowering is a matter of the number of double bonds is a controversial one. Ahrens (cf. Ahrens, Insull, Hirsch, Stoffel, Peterson, Farquhar, Miller \& Thomasson, 1959) maintains that polyunsaturation is the relevant factor and the position or geometrical isomerization of the double bonds is irrelevant. Keys, Anderson \& Grande (1957) maintain that the effect on serum cholesterol is predicted by an equation in which the ratio of saturated to polyunsaturated fat is the relevant factor. On the other hand I have maintained (Sinclair, 1959) that for this ratio the position and geometrical isomerization of the double bonds is important; the fatty acids of the linoleic and linolenic classes tend to lower serum cholesterol, elaeostearic acid (an isomer of linolenic) raises it in the rat (Hegsted, Andrus, Gotsis \& Portman, 1957) and man (Kingsbury, Morgan \& Shervington, 1960), oleic and palmitoleic acids have no effect on it and the same is possibly true of the polyunsaturated acids of these classes, and the long-chain saturated fatty acids tend to raise the serum cholesterol level. Recently Anderson, Grande \& Keys (1961) have shown that in fact trans isomers of linoleic acid do raise the serum cholesterol level 
in man. So far as raising or lowering of serum cholesterol level is concerned, therefore, the number, the position and the geometrical isomerization of double bonds is important. We cannot necessarily equate the lowering with essential-fatty-acid activity, because there might be polyunsaturated fatty acids (e.g. of the $\mathrm{CH}_{2}=\mathrm{CH} .\left(\mathrm{CH}_{2}\right)_{9}$. $\mathrm{COOH}$ class) which lower the serum cholesterol level but, unlike acids of the linoleic and linolenic classes, do not permit growth in rats on a fat-free diet. If we assume that the polyunsaturated fatty acids of the palmitoleic and oleic classes do not lower the serum cholesterol level (they can of course be made in the body), then the fatty acids that lower the serum cholesterol level would appear to be those with the first cis double bond from the methyl end not further than the 6,7-position. Even such a mono-unsaturated acid might be active since it is possible that the body can add further double bonds in the divinyl-methane arrangement towards the carboxyl end, and probably the more the double bonds the greater the lowering when the polyunsaturated fatty acid is eaten. The hexadecatetraenoic acid that occurs in pilchard oil and is $\triangle 1,4,7,10$ (from the methyl end) (Silk \& Hahn, 1954) may be very potent in lowering the serum cholesterol level but presumably has no effect on the skin lesions of rats deficient in essential fatty acids. The lowering has been shown by various authors to occur partly through increased faecal excretion of neutral sterol, perhaps because of the increased solubility of cholesteryl linoleate and similar esters, but mainly through increased katabolism to bile acids. The first stage in this is 7 - $\alpha$-hydroxylation (Bergström, 1959), and it is easy to show with models that the polyunsaturated fatty acids that lower the serum cholesterol level can, if esterified with it, bring a double bond adjacent to this position, whereas those that raise the serum cholesterol level (such as elaeostearic and trans, trans-linoleic acids) cannot.

\section{Influence of some fats on blood coagulation}

This complex subject has been discussed by Poole (1958) and Monkhouse (1960). The only proved effect on blood coagulation in man of eating fat is a shortened clotting time of plasma in presence of Russell's viper venom. Ethanolamine phosphatide (which occurs in chylomicrons, and in two lipoproteins concerned in clotting of blood-platelet factor and Factor III or tissue factor) greatly decreases the clotting time of plasma which has been rapidly centrifuged (Poole, I957); little is found in normal plasma and it in general contains unusually unsaturated fatty acids. I suggested (Sinclair, 1956) on the basis of our results with rats deficient in essential fatty acids that if the fatty acids were more saturated than usual the amount in plasma might increase and so blood would be more coagulable; a two- or three-fold increase in ethanolamine phosphatide has been found in plasma in patients with coronary heart disease (Nothman 8 Proger, I96I).

Adding certain free fatty acids to re-calcified plasma makes it clot quicker; straight-chain saturated fatty acids with sixteen carbon atoms or more have this effect whereas unsaturated fatty acids do not (Poole, 1955; Pilkington, 1957). The fibrinolytic system in man appears to be inhibited by the lipids in butter but not by those in maize or coconut oils, and it is suggested that the actual inhibitory substance is $\beta$-lipoprotein (Greig \& Runde, 1957). 
An increased coagulability of blood after a meal might not be important in coronary thrombosis since the occurrence of this disease is not related in time to meals. As Poole (1959) has pointed out, thrombosis and clotting differ; in the former platelets become packed together, and platelet stickiness is found to be increased after myocardial infarction in man (McDonald \& Edgill, I959). In deficiencies of either essential fatty acids or vitamin $B_{6}$ in the rat Ramalingaswami and I (unpublished) observed in $195^{2}$ that there was increased sludging of erythrocytes, probably as part of the general phenomenon of alteration of cell membranes, and the same might be true of platelets though McDonald \& Edgill (1959) found that coagulability of blood remained unaltered when serum cholesterol was lowered by maize oil in hypercholesterolaemic patients.

\section{Significance of animal and vegetable fats in disease}

There is no evidence that the raising or lowering of the serum level of cholesterol in man necessarily affects atherosclerosis. The most general current hypothesis, which I believe to be wrong, is as follows:

Wrong dietary fats $\longrightarrow$ high blood cholesterol $\rightarrow$ atherosclerosis $\rightarrow$ coronary thrombosis.

As mentioned elsewhere (Sinclair, 1961) the available facts fit better the following diagram:

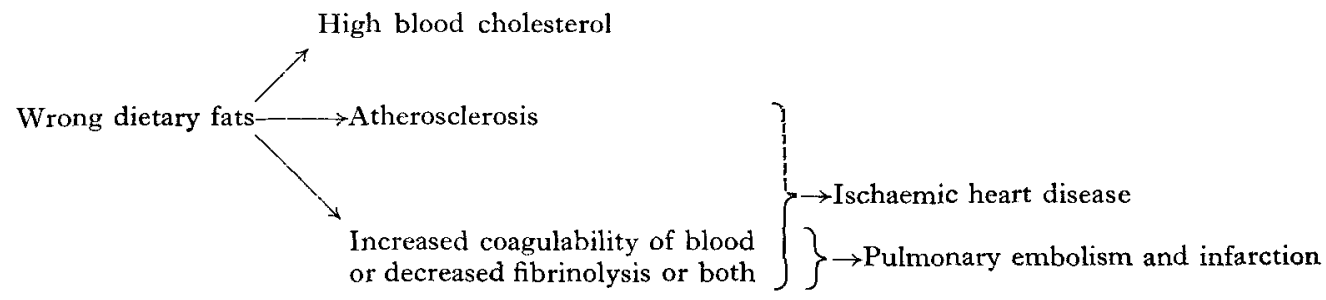

We might try to summarize the very inadequate available facts in a speculative table (Table 2). It might be possible to get atherosclerosis without coronary heart disease by ingestion of a diet high in coconut oil (giving lauric and myristic acids)

Table 2. Effects of different classes of fatty acids

\begin{tabular}{|c|c|c|c|c|}
\hline Class of fatty acid & $\begin{array}{c}\text { Serum } \\
\text { cholesterol }\end{array}$ & Atheroma & $\begin{array}{l}\text { Clotting time } \\
\text { of re-calcified } \\
\text { plasma }\end{array}$ & Fibrinolysis \\
\hline $\begin{array}{l}\text { Saturated } \\
\text { Less than } \mathrm{C}_{16} \\
\mathrm{C}_{16} \text { or more }\end{array}$ & + & $\begin{array}{l}+ \\
+\end{array}$ & $\stackrel{\circ}{+}$ & $\stackrel{\circ}{-}$ \\
\hline $\begin{array}{l}\text { Mono-unsaturated } \\
\text { Oleic }\end{array}$ & $\circ$ & o & o & \\
\hline $\begin{array}{l}\text { Polyunsaturated } \\
\text { EFA }\left\{\begin{array}{l}\text { Linoleic class } \\
\text { Linolenic class }\end{array}\right. \\
\text { Trans-linoleic } \\
\text { Elaeostearic }\end{array}$ & $\begin{array}{l}- \\
- \\
+ \\
+\end{array}$ & $\begin{array}{l}- \\
\overline{+} \\
+\end{array}$ & $\begin{array}{l}0 \\
0 \\
0 \\
0\end{array}$ & + \\
\hline
\end{tabular}

EFA, essential fatty acids; + , increased; - , decreased; 0 , no effect. 
which would not affect greatly the clotting time of re-calcified plasma; such a diet is consumed by Jamaicans who are prone to atherosclerosis but not to ischaemic heart disease (Robertson, 1959). On the other hand, increasing the dietary ratio of stearic acid to linoleic acid, as is the tendency in our diets, would tend to increase the coagulability of blood and so make us prone to ischaemic heart disease and pulmonary infarction, deaths from both of which appear to be increasing in this country at about the same rate.

\section{REFERENCES}

Ahrens, E. H. Jr., Blankenhorn, D. H. \& Tsaltas, T. T. (1954), Proc. Soc. exp. Biol., N.Y., 86, 872. Ahrens, E. H. Jr., Insull, W. Jr., Hirsch, J., Stoffel, W., Peterson, M. L., Farquhar, J. W., Miller, 'T. \& Thomasson, H. J. (1959). Lancet, i, 115.

Anderson, J. T., Grande, F. \& Keys, A. (1961). Fed. Proc. 20, 96.

Atwater, W. O. \& Bryant, A. P. (1900). Rep. (Storrs) agric. Exp. Sta., I 899.

Bergström, S. (1959). In Hormones and Atherosclerosis. [G. Pincus, editor.] New York: Academic Press Inc.

Evans, H. M. \& Lepkovsky, S. (1929). F. biol. Chem. 83, 269.

Greig, H. B. W. \& Runde, I. A. (1957). Lancet, 273, 46 I.

Groen, J., Tjiong, B. K., Kamminga, C. E. \& Willebrands, A. F. (1952). Voeding, 13, 556.

Hegsted, D. M., Andrus, S. B., Gotsis, A. \& Portman, O. W. (r957). F. Nutr. 63, 273.

Hilditch, T. P. (1956). The Chemical Constitution of Natural Fats, 3 rd ed. London: Chapman \& Hall.

Hollingsworth, D. F., Vaughan, M. C. \& Warnock, G. M. (1957). Proc. Nutr. Sac. 15, xvii.

Keys, A. (1953). Y. Mt. Sinai Hosp. 20, 134.

Keys, A., Anderson, J. T. \& Grande, F. (1957). Lancet, 273, 959.

Kingsbury, K. J., Morgan, D. M. \& Shervington, P. (1960). Lancet, ii, 1045.

Kinsell, L. W., Partridge, J., Boling, L., Margen, S. \& Michaels, G. (I952). F. clin. Endocrin. 12, 909.

Kinsell, L. W. \& Sinclair, H. M. (1957). Lancet, 272, 883.

McCann, M. B. \& Trulson, M. F. (1957). F. Amer. diet. Ass. 33, 358.

McDonald, L. \& Edgill, M. (1959). Lancet, ii, i 1 I 5.

Mead, J. F. (г 960$)$. In Lipide Metabolism, Chapter 2. [K. Bloch, editor.] New York: John Wiley \& Sons Inc.

Monkhouse, F. C. (1960). Amer. F. clin. Nutr. 8, I.

Nothman, M. M. \& Proger, S. (196r). Fed. Proc. 20, 90.

Pilkington, T. R. E. (1957). Clin. Sci. x6, 269.

Poole, J. C. F. (1955). Brit. F. exp. Path. 36, 248.

Poole, J. C. F. (1957). In The Lipids and the Clearing Factor, p. 379. Brussels: Palais der Academiën.

Poole, J. C. F. (1958). Brit. med. Bull. r4, no. 3, p. 253.

Poole, J. C. F. (1959). Quart. F. exp. Physiol. 44, 377.

Robertson, W. B. (1959). Lancet, i, 444.

Shorland, F. B. (1950). Nature, Lond., 165, 776.

Silk, M. H. \& Hahn, H. H. (1954). Biochem. F. 57, 582 .

Sinclair, H. M. (1956). Lancet, 270, $3^{81}$.

Sinclair, H. M. (1959). Lancet, i, 474 .

Sinclair, H. M. (196i). F. Atheroscler. Res. r, 8 I.

\section{Hydrogenated oils and polyunsaturated fatty-acid isomers in nutrition}

\section{By E. Aars-Jørgensen, Department of Biochemistry and Nutrition, Polytechnic Institute, Copenhagen}

Hydrogenation is used to change normally liquid oils containing polyenoic fatty acids into semi-solid fats suitable for dietary and manufacturing purposes, e.g. oleomargarine and baking products. Vegetable and marine oils are most commonly used for partial hydrogenations. Vegetable oils contain polyenoic acids of no greater 